Article

\title{
Effects of Natural Antimicrobials on Xanthomonas Strains Growth
}

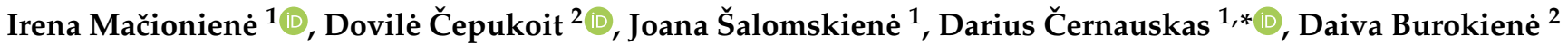 \\ and Alvija Šalaševičiené ${ }^{1}(\mathbb{D}$ \\ 1 Food Institute, Kaunas University of Technology, Radvilènų Avenue 19, LT-50292 Kaunas, Lithuania; \\ irena.macioniene@ktu.lt (I.M.); joana.salomskiene@ktu.lt (J.Š.); alvija.salaseviciene@ktu.lt (A.Š.) \\ 2 Nature Research Centre, Laboratory of Plant Pathology, Akademijos Street 2, LT-08412 Vilnius, Lithuania; \\ dovile.cepukoit@gamtc.lt (D.Č.); daiva.burokiene@gamtc.lt (D.B.) \\ * Correspondence: darius.cernauskas@ktu.lt
}

check for updates

Citation: Mačionienė, I.;

Čepukoit, D.; Šalomskienè, J.;

Černauskas, D.; Burokienè, D.;

Šalaševičienè, A. Effects of Natural

Antimicrobials on Xanthomonas

Strains Growth. Horticulturae 2022, 8,

7. https://doi.org/10.3390/

horticulturae 8010007

Academic Editor: Charalampos

Proestos

Received: 22 November 2021

Accepted: 20 December 2021

Published: 22 December 2021

Publisher's Note: MDPI stays neutral with regard to jurisdictional claims in published maps and institutional affiliations.

Copyright: () 2021 by the authors Licensee MDPI, Basel, Switzerland. This article is an open access article distributed under the terms and conditions of the Creative Commons Attribution (CC BY) license (https:// creativecommons.org/licenses/by/ $4.0 /)$.

\begin{abstract}
The aim of this work was to investigate the most promising natural antimicrobials effective for the growth suppression of Xanthomonas spp. bacteria. The research objects were Xanthomonas spp. strains isolated from tubers and stem of plants growing in Lithuania: Xanthomonas translucens NRCIB X6, X. arboricola NRCIB X7, NRCIB X8, NRCIB X9, and NRCIB X10; the supernatants of lactic acid bacteria Lactococcus lactis strains 140/2, 57, and 768/5, Lactobacillus helveticus strains 14, 148/3, R, and 3, Lb. reuteri 3 and 7, Streptococcus thermophilus 43, Enterococcus faecium 59-30 and 41-2; endophytic bacterial strains Bacillus, Pseudomonas, and Paenibacillus spp.; and essential oils of lavender (Lavandula angustifolia), grapefruit (Citrus paradisi), pine (Pinus sylvestris), thyme (Thymus vulgaris), rosemary (Rosmarinus officinalis), peppermint (Mentha piperita), lemon (Citrus limetta), aqueous extracts of blueberries (Vaccinium myrtillus), and cranberries (Vaccinium vitis-idaea). The antimicrobial activity of tested substances was determined by agar diffusion method. Supernatants of $L b$. reuteri strain 7 and $L b$. helveticus strains $14, \mathrm{R}, 3$, and $148 / 3$ were found to have a high antimicrobial activity against Xanthomonas spp. bacteria strains when compared to the positive control-1.0\% copper sulfate (diameter of inhibition zones was $28.8 \pm 0.7 \mathrm{~mm}$ ). The diameter of inhibition zones of supernatants ranged from $23.3 \pm 0.6 \mathrm{~mm}$ to $32.0 \pm 0.1 \mathrm{~mm}$. Thyme $(2.0 \%)$ and lavender $(2.0 \%)$ essential oils inhibited the growth of Xanthomonas spp. strains. The diameter of the inhibition zones was from $14.7 \pm 0.8 \mathrm{~mm}$ to $22.8 \pm 0.9 \mathrm{~mm}$. The aqueous extracts of blueberries had a weak antimicrobial activity. The diameter of inhibition zones ranged from $11.0 \pm 0.2 \mathrm{~mm}$ to $13.0 \pm 0.2 \mathrm{~mm}$.
\end{abstract}

Keywords: antimicrobial substances; inhibition; phytopathogenic bacteria; Xanthomonas

\section{Introduction}

Bacterial diseases of plants cause devastating damage to crops and significant economic losses [1-3]. They cause about $12 \%$ of plant-origin food loss every year. Phytopathogenic bacteria have the ability to quick adaptation; therefore, eradicating the causes of disease is not an easy task. In addition, climate change scenarios predict that the adaption and migration of plant pathogenic bacteria will accelerate, as changing conditions will help pathogens to spread geographically from Western Europe to the North $[4,5]$.

The bacterial genus Xanthomonas, belonging to the family Xanthomonadaceae, harbour some of the most devastating plant pathogens that continually cause food safety problems. Together, all of these taxa can infect many plants found in agriculture, forest, or natural ecosystems. As many as three species of Xanthomonas are among the ten economically and scientifically significant pathogenic bacteria compiled by scientists [2]. Particular attention has been paid to these species due to the very wide range of plants and the exceptional potential pathogenicity to their plant hosts-the main pathogens of rice and cassava, $X$. oryzae pv. oryzae, and $X$. axonopodis pv. manihotis, respectively, and X. campestris pathovars, which are causal agents of many crops worldwide [2]. 
The aforementioned bacteria causing plant diseases reduce the quantity and quality of the yield obtained. Although various methods of controlling pathogenic bacteria are used, microbiological safety remains a major concern for the agricultural industry. Billions of tons of pesticides are used to fight these plant diseases every year, and many of the antimicrobials currently available are highly toxic, non-biodegradable, and cause significant environmental pollution and rise human health risks [6]. At the present, various compounds, such as copper oxychloride, copper hydroxide, and copper oxide, are used in agriculture to prevent the spread of Xanthomonas spp. bacteria $[7,8]$. However, the widespread use of these agrochemicals increases the resistance of bacterial pathogens and causes significant damage to the environment [6,9].

For these reasons, researchers have focused on plant-derived natural bactericides and their possible applications in agriculture. The search for measures to control plant bacterial diseases are being intensified, as they have enormous potential, and modern agrochemical research is carried out to develop sustainable plant protection strategies and significantly reduce yield losses [10-14]. Naturally occurring and biologically active plant products, such as essential oils, organic extracts, or plant-associated microbiota, could be a source of alternative classes of natural biopesticides and a source of new and more effective compounds suitable for controlling plant pathogenic microorganisms [12,15-17]. In this work, new effective antimicrobials derived from natural sources were sought and therefore economically valuable. Such substances include essential oils, supernatants of lactic acid bacteria, compounds produced by endophytic bacteria, and berry extracts.

The main objective of this work was to assess and select the most effective antibacterial agents in vitro against the pathogenic Xanthomonas spp. strains.

\section{Materials and Methods}

\subsection{Identification of Isolated Endophytic and Xanthomonas spp. Bacteria}

In 2017-2018, plant pathogenic and endophytic bacterial strains from roots and nodules were isolated from the Fabaceae plants in the Laboratory of Plant Pathology at the Nature Research Centre (Vilnius, Lithuania). Phytopathogenic bacteria were isolated from plant material with disease symptoms $[18,19]$. The following Xanthomonas strains were used: $X$. translucens (Xt) NRCIB X6 and X. arboricola (Xa) strains NRCIB X7, NRCIB X8, NRCIB X9, and NRCIB X10.

Endophytic bacteria were isolated from legume roots and nodules. The plants were dug out and placed in sterile plastic bags, taken to the laboratory, and kept in the fridge at $4{ }^{\circ} \mathrm{C}$ until samples were prepared for further analysis. Soil was removed from roots and nodules carefully by gentle washing in running tap water; the surface was sterilized by $70 \%$ ethyl alcohol for $1 \mathrm{~min}$. and followed by a solution of $6 \%$ sodium hypochlorite for 10 min. Samples were rinsed with sterile $\mathrm{dH}_{2} \mathrm{O}$ three times to remove surface sterilization agents. Each root sample was cut into approximately $1-\mathrm{cm}$ fragments and ground in $20 \mu \mathrm{L}$ of sterile water, and 3-5 $\mu \mathrm{L}$ of each root suspension was spread on King's B agar plates and incubated at $27^{\circ} \mathrm{C}$ for $3-5$ days till the colonies of endophytic bacteria developed; then, bacterial colonies were transferred onto the same agar and purified $[18,19]$. Endophytic bacterial strains belonging to Bacillus, Paenibacillus, and Pseudomonas genera were used: Bacillus sp. strains NRCIB B1, NRCIB B2, NRCIB B3, NRCIB B4, NRCIB B5, NRCIB B6, Pseudomonas sp. strains NRCIB P1, NRCIB P2, NRCIB P3, and Paenibacillus sp. NRCIB PB1.

Strains were identified by Gram staining [19]. All gram-negative bacteria were tested for hypersensitive reaction (HR) on tobacco (Nicotiana tabacum L. 'Samsun') [20] and tomato (Solanum lycopersici) plants [18]. A milky suspension $\left(10^{8}\right.$ cells $\left./ \mathrm{mL}\right)$ was infiltrated in the mesophyll between the two epidermis of tobacco and tomato leaves using a small sterile syringe. Plants were evaluated after $24 \mathrm{~h}$, and if the tissues became necrotic, the reaction was considered as positive $[20,21]$. The ability to cause rot on potato and pectolytic activity were investigated; 2-day old bacterial isolates grown on King's B medium at $28{ }^{\circ} \mathrm{C}$ were inoculated in a center of $2.5-\mathrm{cm}$ diameter sterile potato slice placed in a sterile Petri dish on 
moist, sterile filter paper. Pectinolytic properties were evaluated after $24 \mathrm{~h}$ of incubation at $28^{\circ} \mathrm{C}[18,22]$.

All bacterial isolates were selected for further molecular studies: bacterial genomic DNA was extracted using CTAB protocol [23] and Aljanabi and Martinez [24] protocol with slight modifications described by Kałużna et al. [22]. Yellowish Xanthomonas-like bacteria were screened by PCR using genus-specific primers $X 1$ and $X 2$ [25]. PCR reaction mix $(15 \mu \mathrm{L})$ contained $1.5 \mu \mathrm{L} 10 \times$ PCR buffer (Green Buffer DreamTaq, ThermoFisher, Vilnius, Lithuania), $1.3 \mu \mathrm{L}$ dNTPs $(2 \mathrm{mM}), 1 \mu \mathrm{L}$ of each primer (10 pmol), $0.08 \mu \mathrm{L}$ (2 U) Taq DNA polymerase, and $2 \mu \mathrm{L}$ of bacterial DNA $(15 \mathrm{ng})$. PCR was carried out in a thermal cycler (MJ Mini, Biorad, Hercules, CA, USA). Cycling conditions were initial denaturation for 2 min at $95^{\circ} \mathrm{C}$ and 29 cycles of $45 \mathrm{~s}$ at $95^{\circ} \mathrm{C}, 45 \mathrm{~s}$ at $37^{\circ} \mathrm{C}$, and $1.5 \mathrm{~min}$ at $62^{\circ} \mathrm{C}$; the final extension step took $10 \mathrm{~min}$ at $62^{\circ} \mathrm{C}$. The PCR products were visualized on UV by running in a Tris-acetate agarose gel (1.5\%) electrophoresis.

Then, all pathogenic and endophytic bacterial isolates were identified by sequenced bacterial $16 \mathrm{~S}$ rDNA. PCR reaction mix with universal primers $27 \mathrm{~F}$ and $1492 \mathrm{R}$ and amplification conditions according to Lane et al. [26] were used: initial denaturation for $5 \mathrm{~min}$ at $94{ }^{\circ} \mathrm{C}$ and 32 cycles of $1 \mathrm{~min}$ at $94{ }^{\circ} \mathrm{C}, 1 \mathrm{~min}$ at $60{ }^{\circ} \mathrm{C}$, and $1.5 \mathrm{~min}$ at $72{ }^{\circ} \mathrm{C}$; the final extension step took $10 \mathrm{~min}$ at $72{ }^{\circ} \mathrm{C}$. The PCR products were visualized on UV by running in a Tris-acetate agarose gel (1.5\%) electrophoresis. Then, DNA sequence of each strain was subjected to the analysis using DNA LaserGene package National Center for Biotechnology Information database [27].

\subsection{Microorganisms and Growth Media}

This study focuses on twelve lactic acid bacteria (LAB) strains [28] obtained from the Kaunas University of Technology (KTU) Food Institute LAB collection: Enterococcus faecium 59-30, E. faecium 41-2B 2v, Lactobacillus helveticus 14, Lb. helveticus 3, Lb. helveticus 148/3, Lb. helveticus $\mathrm{R}, \mathrm{Lb}$. reuteri 3, Lb. reuteri 7, Lactococcus lactis $140 / 2$, L. lactis 57 , L. lactis $768 / 5$, and Streptococcus thermophilus 43 . Cultures of each bacterial strain were stored at minus $80{ }^{\circ} \mathrm{C}$ in $15 \%$ glycerol. Active bacterial strains for experimental use were prepared by transferring a loopful of cells from stock cultures onto yeast extract calcium carbonate dextrose agar (YDA) (HiMedia, Mumbai, India) at $27^{\circ} \mathrm{C}$ for $24-72 \mathrm{~h}$ (in the case of Xanthomonas spp. and endophytic bacteria) and MRS broth (Oxoid Ltd., Basingstoke, UK) at $30^{\circ} \mathrm{C}$ or $37{ }^{\circ} \mathrm{C}$ for 48 $h$ (in the case of LAB strains).

\subsection{Determination of Antibacterial Activity}

The agar well diffusion method was used to determine the antibacterial activity of substances of natural origin: supernatants of lactic acid bacteria (LAB), essential oils, blueberry and cranberry extracts, and endophytic bacteria obtained from the roots and nodules of Fabaceae plants.

Briefly, the Xanthomonas spp. strains were pre-cultivated on YDA slants for $48 \mathrm{~h}$ at $27 \pm 1{ }^{\circ} \mathrm{C}$. The grown-up bacterial cultures were washed off from the agar with sterile phosphate-buffered saline (PBS) solution $\left(\mathrm{Na}_{2} \mathrm{HPO}_{4} 0.27 \%, \mathrm{NaH}_{2} \mathrm{PO}_{4} 0.04 \%, \mathrm{NaCl} 0.8 \%\right.$, $\mathrm{pH} 7.2$ in distilled water), and the density of cell suspension of each culture was adjusted according to McFarland standard No 0.5. One milliliter of the prepared suspension was added to the YDA medium, melted before, cooled to $45^{\circ} \mathrm{C}$, and was mixed thoroughly. The prepared mixture of bacteria cell suspension and the medium was poured into $90-\mathrm{mm}$ Petri dishes, $12 \mathrm{~mL}$ each. After the medium had solidified, and agar surface had dried, wells of 8-mm diameter were made in the plates, which were filled with $50 \mu \mathrm{L}$ of the examined solution. Antimicrobial effect against the bacterial pathogens was evaluated after $48 \mathrm{~h}$ of growth at $27 \pm 1{ }^{\circ} \mathrm{C}$ according to the diameter (in $\mathrm{mm}$ ) of inhibition zones around the wells. If no inhibition zones formed around the wells, the test solution had no antibacterial effect on the tested bacteria culture. The zones of inhibition (ZOI) were evaluated as follows: 8-9 mm, no effect; $10-15 \mathrm{~mm}$, weak effect; $16-22 \mathrm{~mm}$, medium effect; and $23-32 \mathrm{~mm}$, strong effect. 


\subsection{Cell-Free Supernatants of Lactic Acid Bacteria}

For determining antibacterial activity, $1 \mathrm{~mL}$ of LAB (in sterile milk) was added to $10 \mathrm{~mL}$ of MRS broth (Oxoid, UK) and incubated for $48 \mathrm{~h}$ under the optimal temperature $\left(30{ }^{\circ} \mathrm{C}\right.$ or $37^{\circ} \mathrm{C}$ ). Cell-free supernatants (CFS) were obtained, removing cells by centrifugation at $6000 \mathrm{rpm}$ for $15 \mathrm{~min}$. Then supernatant was filtered through the $0.2-\mu \mathrm{m}$ pore filter.

\subsection{Essential Oils}

Ten essential oils were obtained from commercial sources (UAB “Mèta”, Lithuania). Essential oils of thyme (Thymus vulgaris), grapefruit (Citrus paradisi), lavender (Lavandula angustifolia), rosemary (Rosmarinus officinalis), lemon (Citrus limon), peppermint (Mentha piperita), pine (Pinus sylvestris), tea tree (Melaleuca alternifolia), juniper (Juniperus communis), and silver fir (Abies sibirica) in concentrations of $1.0 \%(v / v)$ and $2.0 \%(v / v)$ were used.

\subsection{Blueberry and Cranberry Aqueous Extracts}

Blueberries (Vaccinium myrtillus) were collected from three different location sites in four countries (Lithuania, Latvia, Finland, and Norway), and cranberries (Vaccinium vitis-idaea) were collected from two different location sites in Lithuania. The berries were harvested during the ripening period (July-September and November) and stored in the freezer at minus $80{ }^{\circ} \mathrm{C}$. For extraction, $5 \mathrm{~g}$ of frozen berries were crushed in a mortar and shaken for $30 \mathrm{~min}$ in $90 \mathrm{~mL}$ of deionized water at $40{ }^{\circ} \mathrm{C}$. Then, the extracts were filtered through Whatman No.1 filter paper. The obtained extracts were transferred into vials and used for further analysis.

\subsection{Determination of Minimum Inhibitory Concentration (MIC)}

The minimum inhibitory concentration (MIC) of antimicrobial essential oils (thyme, grapefruit, lavender) was determined using the broth microdilution method. The test samples of essential oils were dissolved in methanol and added to LB medium (Liofilchem diagnostici, Roseto degli Abruzzi, Italy, ) to get a final concentration of $1000 \mu \mathrm{g} / \mathrm{mL}$, which were further serially diluted to 500, 250, 125, 62.5, 31.25, 15.62, 7.81, and 3.9 $\mathrm{mg} / \mathrm{mL}$, respectively. The final concentration of methanol in the culture medium was maintained at $0.5 \%(v / v)$. A total of $50 \mu \mathrm{L}$ of test organism suspension $\left(1.5 \times 10^{8} \mathrm{CFU} / \mathrm{mL}\right.$ approximately) was transferred into each tube. All tubes, including the control, containing the bacterial suspension in LB medium were incubated at $27 \pm 1^{\circ} \mathrm{C}$ for $48 \mathrm{~h}$. The lowest concentrations of the test samples which, after macroscopic evaluation, did not show any growth of the test organisms, were determined as MICs and were expressed in $\mu \mathrm{g} / \mathrm{mL}$ [29]. All tests were performed in triplicate.

\subsection{Statistical Analysis}

Statistical analysis of test findings was carried out using SPSS 16 package for statistical data processing. Tukey's HSD test was used in order to determine the significant difference $(p<0.05)$ between the obtained research results among inhibition zone sizes against different microorganisms. The tests were repeated $4-5$ times.

\section{Results}

\subsection{Antibacterial Activity of Endophytic Bacterial Strains}

During 2017-2018, plant material from different species of Fabaceae growing in Lithuania was collected. In this study, 295 bacterial isolates were obtained and investigated. All gram-negative bacteria were tested for hypersensitive reaction (HR) on tobacco (Nicotiana tabacum L. 'Samsun') [20], and Xanthomonas-like isolates were tested on tomato (Solanum lycopersici) plants (Figure 1) [18]. Xanthomonas-like isolates showing pathogenicity to tomato plants and having pectolytic activity were identified by 480-bp band produced in PCR using genus-specific primers X1 and X2 [25]. The approximately 1300-bp PCR product of the 16S DNA fragment [26] was then sequenced. Our studies revealed that only five isolates belong to the genus Xanthomonas: one strain was classified as X. translucens (Xt) 
(NRCIB X6) and four as X. arboricola (Xa) (NRCIB X7, NRCIB X8, NRCIB X9, and NRCIB X10) (accession numbers in GenBank: OL504772-OL504776).

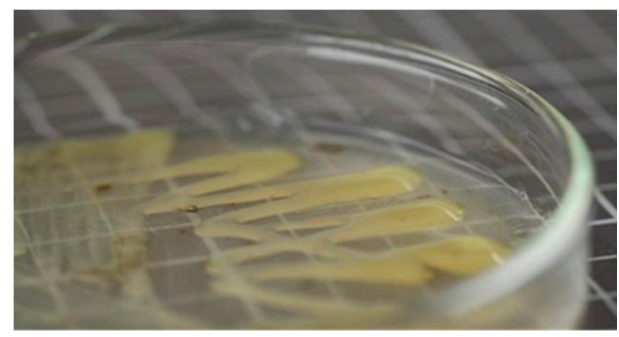

(a)

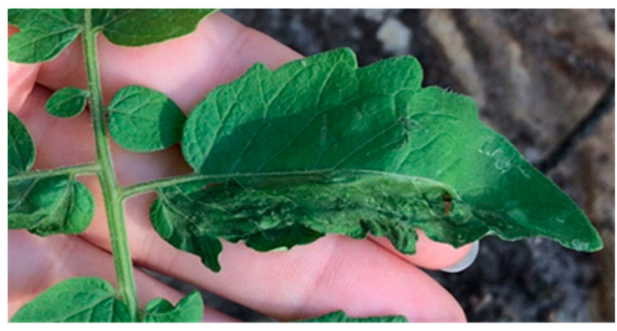

(b)

Figure 1. The yellowish bacteria X. arboricola NRCIB X8 (a) and hypersensitive reaction test on tomato (b).

Endophytic bacteria can protect the plant from pathogens. Thus, 10 out of 73 endophytic non-pathogenic isolates without pectolytic activity were selected as the most effective isolates against pathogenic Xanthomonas strains (Table 1). These bacteria were identified by sequenced 16S rDNA (accession numbers in GenBank: OL505113-OL505122).

Table 1. Antibacterial activity of different endophytic bacterial strains against pathogenic Xanthomonas spp. strains.

\begin{tabular}{|c|c|c|c|c|c|}
\hline \multirow{3}{*}{ Antagonistic Bacteria Strain } & \multicolumn{5}{|c|}{ Average Zone of Inhibition (ZOI), mm } \\
\hline & \multicolumn{5}{|c|}{ Xanthomonas spp. Strain } \\
\hline & $\begin{array}{l}\text { X. translucens } \\
\text { NRCIB X6 }\end{array}$ & $\begin{array}{l}\text { X. arboricola } \\
\text { NRCIB X7 }\end{array}$ & $\begin{array}{l}\text { X. arboricola } \\
\text { NRCIB X8 }\end{array}$ & $\begin{array}{l}\text { X. arboricola } \\
\text { NRCIB X9 }\end{array}$ & $\begin{array}{c}\text { X. arboricola } \\
\text { NRCIB X10 }\end{array}$ \\
\hline Pseudomonas sp. NRCIB P2 & $33.0 \pm 0.0 \mathrm{~d}$ & $33.0 \pm 0.0 \mathrm{~d}$ & $25.9 \pm 0.5 b, f$ & $24.1 \pm 0.4 \mathrm{a}, \mathrm{f}, \mathrm{g}$ & $23.0 \pm 0.5 \mathrm{~b}, \mathrm{~d}, \mathrm{~g}$ \\
\hline Pseudomonas sp. NRCIB P1 & $32.7 \pm 0.8 \mathrm{~d}$ & $31.2 \pm 0.7 c$ & $23.2 \pm 0.3 \mathrm{a}, \mathrm{e}, \mathrm{i}$ & $24.0 \pm 1.5 \mathrm{a}, \mathrm{e}, \mathrm{g}$ & $23.7 \pm 0.3 b, d, f, g$ \\
\hline Pseudomonas sp. NRCIB P3 & $27.2 \pm 0.4 \mathrm{e}$ & $25.5 \pm 0.6 \mathrm{~b}$ & $25.1 \pm 0.8 \mathrm{a}, \mathrm{b}, \mathrm{g}$ & $22.5 \pm 0.6 \mathrm{~d}, \mathrm{~g}$ & $24.8 \pm 1.4 \mathrm{c}, \mathrm{g}$ \\
\hline Bacillus sp. NRCIB B5 & $24.6 \pm 0.0 \mathrm{c}$ & $25.2 \pm 0.3 b$ & $22.7 \pm 0.3 c, d, e, g$ & $22.9 \pm 0.1 \mathrm{c}, \mathrm{d}, \mathrm{e}, \mathrm{f}$ & $22.2 \pm 0.2 \mathrm{~d}, \mathrm{i}$ \\
\hline Bacillus sp. NRCIB B4 & $21.8 \pm 0.5 \mathrm{a}, \mathrm{g}$ & $21.5 \pm 0.6 \mathrm{a}$ & $25.1 \pm 0.7 \mathrm{a}, \mathrm{b}$ & $26.2 \pm 1.1 \mathrm{a}$ & $24.5 \pm 1.4 \mathrm{~b}, \mathrm{c}$ \\
\hline Bacillus sp. NRCIB B1 & $22.2 \pm 0.1 \mathrm{a}$ & $21.0 \pm 0.1 \mathrm{a}$ & $23.5 \pm 0.2 \mathrm{a}, \mathrm{c}, \mathrm{f}$ & $25.1 \pm 0.6 \mathrm{a}, \mathrm{c}$ & $25.2 \pm 0.2 \mathrm{a}, \mathrm{c}, \mathrm{f}$ \\
\hline Bacillus sp. NRCIB B2 & - & $21.4 \pm 0.2 \mathrm{a}$ & $25.3 \pm 0.2 \mathrm{a}, \mathrm{b}$ & $30.3 \pm 0.5 \mathrm{~b}$ & $27.0 \pm 0.4 \mathrm{a}$ \\
\hline Bacillus sp. NRCIB B3 & $21.2 \pm 0.9 \mathrm{a}, \mathrm{g}$ & $20.6 \pm 0.4 \mathrm{a}$ & $26.8 \pm 2.2 \mathrm{~b}$ & $25.4 \pm 1.3 \mathrm{a}$ & $23.0 \pm 0.0 \mathrm{~b}, \mathrm{~d}, \mathrm{~g}$ \\
\hline Bacillus sp. NRCIB B6 & $22.8 \pm 0.8 \mathrm{a}$ & $20.6 \pm 0.2 \mathrm{a}$ & $20.6 \pm 0.1 \mathrm{~d}$ & $21.6 \pm 0.3 \mathrm{~d}$ & $22.4 \pm 0.2 \mathrm{~d}, \mathrm{e}, \mathrm{i}$ \\
\hline Paenibacillus sp. NRCIB PB1 & $30.3 \pm 0.2 \mathrm{f}$ & $20.7 \pm 0.3 \mathrm{a}$ & $16.5 \pm 0.2 \mathrm{~h}$ & $17.0 \pm 0.1 \mathrm{~h}$ & $16.4 \pm 0.6 \mathrm{~h}$ \\
\hline$K^{*}$ & $20.3 \pm 1.2 \mathrm{~g}$ & $21.8 \pm 0.8 \mathrm{a}$ & $21.0 \pm 0.9 \mathrm{~d}, \mathrm{i}$ & $20.8 \pm 0.6 \mathrm{~d}, \mathrm{i}$ & $20.5 \pm 0.6 \mathrm{i}$ \\
\hline
\end{tabular}

* - control solution $\left(1 \% \mathrm{CuSO}_{4}\right)$. Note: The values with different letters in a column are significantly different at $p<0.05\left(1 \% \mathrm{CuSO}_{4}\right)$.

All endophytic bacteria tested belong to the genera Pseudomonas, Bacillus, and Paenibacillus. However, Pseudomonas spp. bacteria, especially Pseudomonas sp. strain NRCIB P2 (average ZOI ranged from $23.00 \pm 0.47 \mathrm{~mm}$ to $33.00 \pm 0 \mathrm{~mm}$ ), had a stronger inhibitory effect on pathogenic Xanthomonas spp. than other endophytic bacteria. The efficacy of some bacterial strains has been found to depend on the species of pathogenic microorganism. Paenibacillus sp. NRCIB PB1 showed significantly greater inhibition against $X$. translucens NRCIB X6 (average ZOI $30.28 \pm 0.25 \mathrm{~mm}$ ) compared to X. arboricola strains (average ZOI ranged from $16.43 \pm 0.58 \mathrm{~mm}$ to $20.68 \pm 0.33 \mathrm{~mm}$ ), but Bacillus sp. NRCIB B2 was not effective against $X$. translucens NRCIB X6 and inhibited colony growth of X. arboricola strains (average ZOI ranged from $21.33 \pm 0.24 \mathrm{~mm}$ to $30.3 \pm 0.46 \mathrm{~mm}$ ).

\subsection{Lactic Acid Bacteria Strains}

In our study, the tested LAB strains that exposed antibacterial activity against Xanthomonas spp. strains were chosen for further analysis (Table 2). The data in Table 2 showed that LAB strains and their supernatants were antimicrobially active against Xanthomonas spp. strains' growth. Comparing the antibacterial activity among LAB strains, supernatants of $L b$. helveticus $148 / 3,3$, and 14 demonstrated a strong inhibitory effect against 
Xanthomonas spp. strains (average ZOI ranged from $23.3 \pm 1.0 \mathrm{~mm}$ to $32.0 \pm 0.2 \mathrm{~mm}$ ) (Figure 2).

Table 2. Antibacterial activity of different LAB strains against Xanthomonas spp. strains.

\begin{tabular}{|c|c|c|c|c|c|}
\hline \multirow{3}{*}{ Lactic acid Bacteria Strain } & \multicolumn{5}{|c|}{ Average Zone of Inhibition (ZOI), mm } \\
\hline & \multicolumn{5}{|c|}{ Xanthomonas spp. Strain } \\
\hline & $\begin{array}{l}\text { X. translucens } \\
\text { NRCIB X6 }\end{array}$ & $\begin{array}{c}\text { X. arboricola } \\
\text { NRCIB X7 }\end{array}$ & $\begin{array}{c}\text { X. arboricola } \\
\text { NRCIB X8 }\end{array}$ & $\begin{array}{c}\text { X. arboricola } \\
\text { NRCIB X9 }\end{array}$ & $\begin{array}{c}\text { X. arboricola } \\
\text { NRCIB X10 }\end{array}$ \\
\hline L. lactis $140 / 2$ & $20.1 \pm 0.6 \mathrm{a}$ & $20.9 \pm 1.0 \mathrm{a}$ & $20.6 \pm 0.8 \mathrm{a}$ & $22.0 \pm 1.0 \mathrm{~b}, \mathrm{e}$ & $22.5 \pm 1.0 \mathrm{a}$ \\
\hline L. lactis 57 & $19.1 \pm 0.9 \mathrm{a}$ & $20.0 \pm 0.2 \mathrm{a}, \mathrm{b}$ & $19.8 \pm 1.0 \mathrm{a}$ & $20.0 \pm 1.0 \mathrm{a}, \mathrm{b}$ & $22.0 \pm 1.0 \mathrm{a}$ \\
\hline L. lactis $768 / 5$ & $18.5 \pm 0.6 \mathrm{a}$ & $18.3 \pm 0.5 \mathrm{~b}$ & $19.3 \pm 0.7 \mathrm{a}$ & $18.5 \pm 0.6 \mathrm{a}$ & $20.8 \pm 1.0 \mathrm{a}$ \\
\hline E. faecium 59/30 & $17.9 \pm 0.3 \mathrm{a}$ & $19.8 \pm 0.5 \mathrm{a}, \mathrm{b}$ & $19.0 \pm 0.8 \mathrm{a}$ & $19.0 \pm 0.8 \mathrm{a}$ & $20.5 \pm 0.6 \mathrm{a}$ \\
\hline E. faecium $41 / 2$ & $19.3 \pm 0.5 \mathrm{a}$ & $20.3 \pm 1.0 \mathrm{a}, \mathrm{b}$ & $19.8 \pm 0.5 \mathrm{a}$ & $19.5 \pm 0.6 \mathrm{a}$ & $20.8 \pm 0.8 \mathrm{a}$ \\
\hline Lb. helveticus 14 & $23.3 \pm 1.0 \mathrm{c}$ & $29.0 \pm 0.8 \mathrm{c}, \mathrm{g}$ & $25.3 \pm 1.0 \mathrm{c}$ & $28.8 \pm 1.2 \mathrm{c}$ & $26.5 \pm 1.0 \mathrm{c}$ \\
\hline Lb. helveticus 3 & $29.5 \pm 1.0 \mathrm{~b}, \mathrm{~d}$ & $28.5 \pm 1.0 \mathrm{~d}, \mathrm{e}$ & $28.3 \pm 1.0 \mathrm{c}, \mathrm{d}$ & $28.5 \pm 1.0 \mathrm{c}, \mathrm{d}$ & $30.0 \pm 0.8 \mathrm{~b}, \mathrm{~d}, \mathrm{e}$ \\
\hline Lb. helveticus $148 / 3$ & $32.0 \pm 0.8 \mathrm{~b}$ & $29.3 \pm 1.0 \mathrm{c}, \mathrm{g}$ & $32.0 \pm 0.2 \mathrm{~b}$ & $28.8 \pm 1.0 \mathrm{c}, \mathrm{d}$ & $30.0 \pm 0.8 \mathrm{~b}, \mathrm{~d}, \mathrm{e}$ \\
\hline Lb. helveticus $\mathrm{R}$ & $27.3 \pm 1.0 \mathrm{~d}, \mathrm{f}$ & $27.0 \pm 1.0 \mathrm{c}, \mathrm{d}$ & $27.3 \pm 1.0 \mathrm{c}, \mathrm{d}$ & $27.0 \pm 1.0 \mathrm{~d}$ & $31.0 \pm 1.0 \mathrm{~b}$ \\
\hline S. thermophilus 43 & $19.8 \pm 0.5 \mathrm{a}$ & $18.8 \pm 0.5 \mathrm{~b}, \mathrm{f}$ & $20.0 \pm 0.8 \mathrm{a}$ & $18.9 \pm 1.0 \mathrm{a}$ & $21.5 \pm 1.0 \mathrm{a}$ \\
\hline Lb. reuteri 3 & $27.1 \pm 1.0 \mathrm{~d}, \mathrm{e}, \mathrm{f}$ & $24.5 \pm 0.6 \mathrm{e}$ & $27.3 \pm 1.2 \mathrm{c}, \mathrm{d}$ & $24.8 \pm 1.0 \mathrm{e}$ & $26.0 \pm 1.0 \mathrm{c}, \mathrm{d}$ \\
\hline Lb. reuteri 7 & $26.0 \pm 1.0 \mathrm{f}$ & $25.3 \pm 1.0 \mathrm{~d}, \mathrm{e}$ & $27.0 \pm 1.0 \mathrm{c}, \mathrm{d}$ & $28.0 \pm 1.2 \mathrm{c}, \mathrm{d}$ & $26.8 \pm 1.0 \mathrm{c}, \mathrm{e}$ \\
\hline $\mathrm{K}^{*}$ & $28.3 \pm 1.0 \mathrm{~d}, \mathrm{f}, \mathrm{g}$ & $29.8 \pm 0.5 \mathrm{~g}$ & $29.0 \pm 1.0 \mathrm{~b}, \mathrm{~d}$ & $28.8 \pm 1.0 \mathrm{c}, \mathrm{d}$ & $28.5 \pm 1.0 \mathrm{~b}, \mathrm{c}$ \\
\hline
\end{tabular}

*-control solution $\left(1 \% \mathrm{CuSO}_{4}\right)$. Note: The values with different letters in a column are significantly different at $p<0.05$.

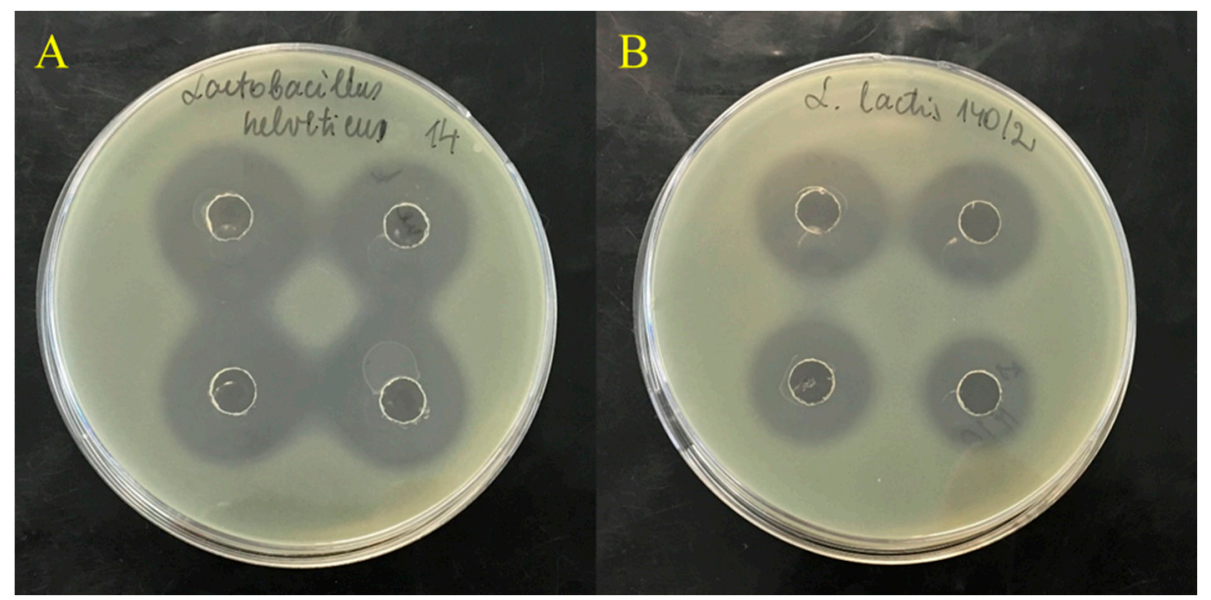

Figure 2. Antibacterial activity of Lb. helveticus 14 (A) and L. lactis 140/2 (B) strains against X. arboricola NRCIB X7.

Lb. reuteri 3 supernatant also showed the strong activity against the growth of $X$. translucens NRCIB X6 (ZOI was $27.3 \pm 1.2 \mathrm{~mm}$ ) and X. arboricola NRCIB X8 (ZOI was $27.3 \pm 1.2 \mathrm{~mm})$. Supernatant of $L b$. reuteri 7 inhibited the growth of X. arboricola NRCIB X9 strongly (ZOI was $28.0 \pm 1.2 \mathrm{~mm}$ ).

The scientific literature suggests that the size of the zone of inhibition depends on the type of LAB, the test method, and the concentration of LAB [30]. L. lactis, E. faecium and $S$. thermophilus strains showed a moderate antibacterial effect (ZOI ranged from $17.9 \pm 0.3 \mathrm{~mm}$ to $22.0 \pm 1.0 \mathrm{~mm}$ ). The results demonstrated the influence of genus and species on the potential in select of LAB or endophytic strains with enhanced antibacterial activities against Xanthomonas spp. strains. 


\subsection{Essential Oils and Aqueous Extracts of Berries}

The antimicrobial activity of plant oils and extracts has been recognized for many years $[12,16,17,31]$. In our study, we tested different essential oils and obtained that the tested essential oils exposed antibacterial activity against Xanthomonas spp. strains' growth (Table 3).

Table 3. Antibacterial effect of essential oils on Xanthomonas spp. strains.

\begin{tabular}{|c|c|c|c|c|c|c|}
\hline \multirow{3}{*}{ Essential Oil } & \multirow{3}{*}{ Concentration, $\%$} & \multicolumn{5}{|c|}{ Average Zone of Inhibition, $\mathrm{mm}$} \\
\hline & & \multicolumn{5}{|c|}{ Xanthomonas spp. Strain } \\
\hline & & $\begin{array}{c}\text { X. translucens } \\
\text { NRCIB X6 }\end{array}$ & $\begin{array}{l}\text { X. arboricola } \\
\text { NRCIB X7 }\end{array}$ & $\begin{array}{l}\text { X. arboricola } \\
\text { NRCIB X8 }\end{array}$ & $\begin{array}{l}\text { X. arboricola } \\
\text { NRCIB X9 }\end{array}$ & $\begin{array}{c}\text { X. arboricola } \\
\text { NRCIB X10 }\end{array}$ \\
\hline Rosemary & 1 & $0.0 \pm 0.0 \mathrm{~b}$ & $0.0 \pm 0.0 c$ & $9.0 \pm 0.1 \mathrm{i}$ & $0.0 \pm 0.0 \mathrm{~b}$ & $0.0 \pm 0.0 c$ \\
\hline (Rosmarinus officinalis) & 2 & $0.0 \pm 0.0 \mathrm{~b}$ & $0.0 \pm 0.0 \mathrm{c}$ & $10.0 \pm 0.1 \mathrm{e}$ & $11.0 \pm 0.0 \mathrm{~g}, \mathrm{~h}, \mathrm{i}$ & $9.0 \pm 0.0 \mathrm{~h}$ \\
\hline Lemon & 1 & $0.0 \pm 0.0 \mathrm{~b}$ & $0.0 \pm 0.0 c$ & $0.0 \pm 0.0 \mathrm{~b}$ & $0.0 \pm 0.0 \mathrm{~b}$ & $0.0 \pm 0.0 c$ \\
\hline (Citrus limon) & 2 & $0.0 \pm 0.0 \mathrm{~b}$ & $0.0 \pm 0.0 \mathrm{c}$ & $0.0 \pm 0.0 \mathrm{~b}$ & $0.0 \pm 0.0 \mathrm{~b}$ & $0.0 \pm 0.0 c$ \\
\hline Thyme & 1 & $16.0 \pm 0.0 \mathrm{c}$ & $11.0 \pm 0.0 \mathrm{a}$ & $16.5 \pm 0.1 c$ & $14.0 \pm 0.0 \mathrm{c}$ & $17.0 \pm 0.1 \mathrm{~d}$ \\
\hline (Thymus vulgaris) & 2 & $22.0 \pm 0.1 \mathrm{~d}$ & $18.0 \pm 0.1 \mathrm{~d}$ & $20.0 \pm 0.1 \mathrm{~d}$ & $28.0 \pm 0.2 \mathrm{~d}$ & $26.0 \pm 0.2 \mathrm{e}$ \\
\hline Grapefruit & 1 & $11.0 \pm 0.1 \mathrm{e}$ & $10.0 \pm 0.1 \mathrm{e}$ & $10.0 \pm 0.1 \mathrm{e}$ & $10.5 \pm 0.2 \mathrm{e}, \mathrm{h}$ & $10.0 \pm 0.0 \mathrm{a}$ \\
\hline (Citrus paradisi) & 2 & $14.5 \pm 0.5 \mathrm{f}$ & $11.0 \pm 0.1 \mathrm{a}$ & $11.0 \pm 0.1 \mathrm{f}$ & $12.3 \pm 0.2 \mathrm{a}$ & $12.0 \pm 0.1 \mathrm{f}$ \\
\hline Peppermint & 1 & $0.0 \pm 0.0 \mathrm{~b}$ & $0.0 \pm 0.0 c$ & $0.0 \pm 0.0 \mathrm{~b}$ & $0.0 \pm 0.0 \mathrm{~b}$ & $0.0 \pm 0.0 \mathrm{c}$ \\
\hline (Mentha piperita) & 2 & $11.0 \pm 0.1 \mathrm{e}, \mathrm{g}$ & $10.0 \pm 0.0 \mathrm{e}$ & $11.0 \pm 0.0 \mathrm{f}, \mathrm{h}$ & $10.0 \pm 0.0 \mathrm{e}$ & $11.0 \pm 0.0 \mathrm{~b}$ \\
\hline Pine & 1 & $0.0 \pm 0.0 \mathrm{~b}$ & $0.0 \pm 0.0 \mathrm{c}$ & $0.0 \pm 0.0 \mathrm{~b}$ & $0.0 \pm 0.0 \mathrm{~b}$ & $0.0 \pm 0.0 \mathrm{c}$ \\
\hline (Pinus sylvestris) & 2 & $0.0 \pm 0.0 \mathrm{~b}$ & $0.0 \pm 0.0 c$ & $0.0 \pm 0.0 \mathrm{~b}$ & $0.0 \pm 0.0 \mathrm{~b}$ & $0.0 \pm 0.0 \mathrm{c}$ \\
\hline Lavender & 1 & $11.5 \pm 0.1 \mathrm{a}, \mathrm{e}$ & $11.5 \pm 0.0 \mathrm{f}$ & $11.5 \pm 0.0 \mathrm{a}, \mathrm{f}$ & $11.5 \pm 0.1 \mathrm{a}, \mathrm{i}$ & $10.5 \pm 0.0 \mathrm{a}, \mathrm{b}$ \\
\hline (Lavandula angustifolia) & 2 & $15.0 \pm 0.0 \mathrm{f}$ & $15.0 \pm 0.1 \mathrm{~g}$ & $14.5 \pm 0.0 \mathrm{~g}$ & $15.5 \pm 0.1 \mathrm{f}$ & $13.5 \pm 0.0 \mathrm{~g}$ \\
\hline Tea tree & 1 & $11.5 \pm 0.0 \mathrm{a}, \mathrm{e}$ & $11.2 \pm 0.1 \mathrm{a}, \mathrm{f}$ & $11.3 \pm 0.2 \mathrm{a}, \mathrm{f}$ & $11.5 \pm 0.0 \mathrm{a}, \mathrm{g}$ & $10.0 \pm 0.1 \mathrm{a}$ \\
\hline (Melaleuca alterfolia) & 2 & $12.0 \pm 0.1 \mathrm{a}$ & $12.0 \pm 0.1 \mathrm{~b}$ & $12.0 \pm 0.1 \mathrm{a}$ & $12.0 \pm 0.1 \mathrm{a}$ & $11.0 \pm 0.2 \mathrm{~b}$ \\
\hline Silver fir & 1 & $0.0 \pm 0.0 \mathrm{~b}$ & $0.0 \pm 0.0 c$ & $0.0 \pm 0.0 \mathrm{~b}$ & $0.0 \pm 0.0 \mathrm{~b}$ & $0.0 \pm 0.0 c$ \\
\hline (Abies sibirica) & 2 & $0.0 \pm 0.0 \mathrm{~b}$ & $0.0 \pm 0.0 \mathrm{c}$ & $0.0 \pm 0.0 \mathrm{~b}$ & $0.0 \pm 0.0 \mathrm{~b}$ & $0.0 \pm 0.0 \mathrm{c}$ \\
\hline Juniper & 1 & $0.0 \pm 0.0 \mathrm{~b}$ & $0.0 \pm 0.0 c$ & $0.0 \pm 0.0 \mathrm{~b}$ & $0.0 \pm 0.0 \mathrm{~b}$ & $0.0 \pm 0.0 c$ \\
\hline (Juniperus communis) & 2 & $0.0 \pm 0.0 \mathrm{~b}$ & $0.0 \pm 0.0 c$ & $0.0 \pm 0.0 \mathrm{~b}$ & $0.0 \pm 0.0 \mathrm{~b}$ & $0.0 \pm 0.0 \mathrm{c}$ \\
\hline
\end{tabular}

Note: The values with different letters in a column are significantly different at $p<0.05$.

The results showed that the tested essential oils had a different antibacterial activity against Xanthomonas spp. strains. The 1\% (v/v) essential oils of lemon, pine, silver fir, juniper, rosemary, and peppermint had no antibacterial activity. Weak antibacterial activity was found in $2 \%(v / v)$ essential oils of grapefruit, lavender, tea tree, and peppermint. The $2 \%(v / v)$ thyme essential oils showed a medium to strong antibacterial activity (ZOI ranged from $18.0 \pm 0.1 \mathrm{~mm}$ to $28.0 \pm 0.2 \mathrm{~mm}$ ) (Figure 3). Our finding that tested emulsions of essential oils possessed an antibacterial activity against Xanthomonas spp. is in close agreement with the previously reported results $[16,29,32]$.

The efficiently of essential oils (thyme, lavender, and grapefruit) on investigated Xanthomonas strains was assessed by determining the minimum inhibitory concentration.

Essential oils of thyme, lavender, and grapefruit exhibited a strong antibacterial activity against Xanthomonas spp. The minimum inhibitory concentration values were 7.81-31.25 $\mu \mathrm{g} / \mathrm{mL}$. All Xanthomonas spp. strains were found to be the most sensitive organisms to thyme essential oil (MIC value $7.81 \mu \mathrm{g} / \mathrm{mL}$ ).

Aqueous extracts of blueberries and cranberries showed a weak and moderate inhibitory effect in vitro against Xanthomonas spp. strains (Table 4). Based on the results obtained, the antibacterial efficacy of blueberry extracts does not depend on the region (country) or their habitat. Inhibition of blueberry extracts resulted in zones of inhibition whose diameters were ranging from $10.0 \pm 0.1 \mathrm{~mm}$ to $13.0 \pm 0.0 \mathrm{~mm}$. That indicates a weak antibacterial effect against Xanthomonas spp. bacterial strains. Aqueous cranberry extracts showed sufficiently moderate antibacterial activity-the average of inhibition zones ranged from $17.5 \pm 0.5 \mathrm{~mm}$ to $18.1 \pm 0.2 \mathrm{~mm}$ (location site No. 1 ). 


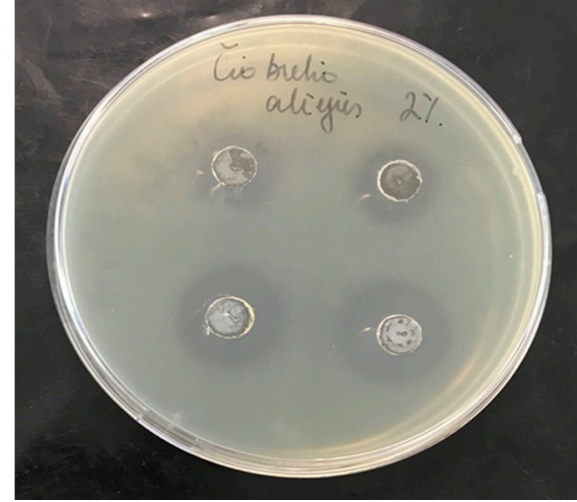

(a)

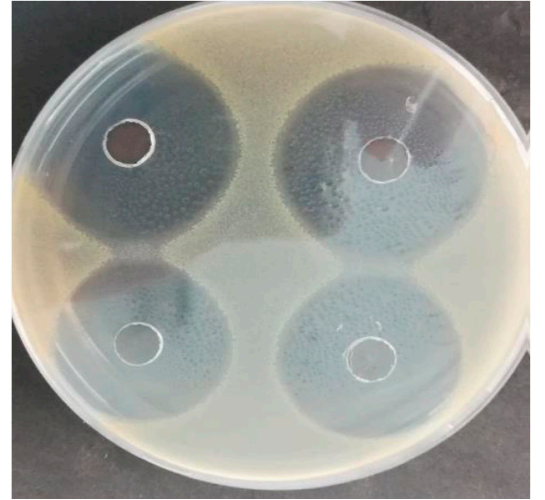

(b)

Figure 3. Antibacterial activity of thyme (Thymus vulgaris) essential oils concentration 1\% (a) and 2\% (b) against X. arboricola NRCIB X7.

Table 4. Antibacterial activity of blueberry and cranberry aqueous extracts against Xanthomonas spp. strains.

\begin{tabular}{|c|c|c|c|c|c|c|}
\hline \multirow{3}{*}{$\begin{array}{l}\text { Berry Extract } \\
\text { (Country) }\end{array}$} & \multirow{3}{*}{$\begin{array}{l}\text { Berry Location } \\
\text { Sites Number }\end{array}$} & \multicolumn{5}{|c|}{ Average Zone of Inhibition, $\mathrm{mm}$} \\
\hline & & \multicolumn{5}{|c|}{ Xanthomonas spp. Strains } \\
\hline & & $\begin{array}{l}\text { X. translucens } \\
\text { NRCIB X6 }\end{array}$ & $\begin{array}{c}\text { X. arboricola } \\
\text { NRCIB X7 }\end{array}$ & $\begin{array}{c}\text { X. arboricola } \\
\text { NRCIB X8 }\end{array}$ & $\begin{array}{c}\text { X. arboricola } \\
\text { NRCIB X9 }\end{array}$ & $\begin{array}{c}\text { X. arboricola } \\
\text { NRCIB X10 }\end{array}$ \\
\hline \multirow{3}{*}{$\begin{array}{l}\text { Blueberry } \\
\text { (Lithuania) }\end{array}$} & 1 & $11.0 \pm 0.0 \mathrm{a}$ & $11.0 \pm 0.0 \mathrm{a}$ & $11.0 \pm 0.0 \mathrm{a}$ & $11.5 \pm 0.0 \mathrm{a}, \mathrm{c}, \mathrm{e}, \mathrm{f}, \mathrm{g}, \mathrm{h}, \mathrm{j}, \mathrm{k}$ & $12.0 \pm 0.0 \mathrm{a}$ \\
\hline & 2 & $11.0 \pm 0.0 \mathrm{a}$ & $11.0 \pm 0.0 \mathrm{a}$ & $11.0 \pm 0.0 \mathrm{a}$ & $11.0 \pm 0.0 \mathrm{a}, \mathrm{b}$ & $12.0 \pm 0.0 \mathrm{a}$ \\
\hline & 3 & $11.0 \pm 0.0 \mathrm{a}$ & $10.0 \pm 0.0 \mathrm{~b}$ & $10.0 \pm 0.1 \mathrm{~b}$ & $12.0 \pm 0.0 \mathrm{c}$ & $13.0 \pm 0.0 \mathrm{~b}$ \\
\hline \multirow{3}{*}{ Blueberry (Finland) } & 1 & $10.0 \pm 0.0 \mathrm{~b}$ & $10.0 \pm 0.0 \mathrm{~b}$ & $10.0 \pm 0.0 \mathrm{~b}$ & $11.0 \pm 0.0 \mathrm{~b}, \mathrm{j}$ & $11.0 \pm 0.0 \mathrm{c}$ \\
\hline & 2 & $10.0 \pm 0.0 \mathrm{~b}$ & $10.0 \pm 0.0 \mathrm{~b}$ & $10.0 \pm 0.0 \mathrm{~b}$ & $11.0 \pm 0.0 \mathrm{~b}, \mathrm{k}$ & $11.0 \pm 0.0 \mathrm{c}$ \\
\hline & 3 & $10.0 \pm 0.0 \mathrm{~b}$ & $10.0 \pm 0.0 \mathrm{~b}$ & $10.0 \pm 0.0 \mathrm{~b}$ & $12.0 \pm 0.0 \mathrm{c}, 1$ & $12.0 \pm 0.0 \mathrm{a}$ \\
\hline \multirow{3}{*}{ Blueberry (Latvia) } & 1 & $11.0 \pm 0.0 \mathrm{a}$ & $11.0 \pm 0.0 \mathrm{a}$ & $11.0 \pm 0.0 \mathrm{a}$ & $12.0 \pm 0.0 \mathrm{c}, \mathrm{d}$ & $12.0 \pm 0.0 \mathrm{a}$ \\
\hline & 2 & $11.0 \pm 0.0 \mathrm{a}$ & $11.0 \pm 0.0 \mathrm{a}$ & $11.0 \pm 0.0 \mathrm{a}$ & $11.0 \pm 0.0 \mathrm{~b}, \mathrm{e}$ & $11.0 \pm 0.0 \mathrm{c}$ \\
\hline & 3 & $11.0 \pm 0.1 \mathrm{a}$ & $11.0 \pm 0.0 \mathrm{a}$ & $11.0 \pm 0.0 \mathrm{a}$ & $11.2 \pm 0.0 \mathrm{~b}, \mathrm{f}$ & $11.0 \pm 0.0 \mathrm{c}$ \\
\hline \multirow{3}{*}{ Blueberry (Norway) } & 1 & $10.0 \pm 0.0 \mathrm{~b}$ & $10.0 \pm 0.0 \mathrm{~b}$ & $10.0 \pm 0.0 \mathrm{~b}$ & $11.0 \pm 0.0 \mathrm{~b}, \mathrm{~g}$ & $11.0 \pm 0.0 \mathrm{c}$ \\
\hline & 2 & $10.0 \pm 0.0 \mathrm{~b}$ & $10.0 \pm 0.0 \mathrm{~b}$ & $10.0 \pm 0.0 \mathrm{~b}$ & $11.0 \pm 0.0 \mathrm{~b}, \mathrm{~h}$ & $11.0 \pm 0.0 \mathrm{c}$ \\
\hline & 3 & $11.0 \pm 0.0 \mathrm{a}$ & $11.0 \pm 0.0 \mathrm{a}$ & $11.0 \pm 0.0 \mathrm{a}$ & $12.0 \pm 0.0 \mathrm{c}, \mathrm{i}$ & $12.0 \pm 0.0 \mathrm{a}$ \\
\hline Cranberry & 1 & $17.8 \pm 0.3 \mathrm{c}$ & $18.1 \pm 0.2 \mathrm{c}$ & $17.8 \pm 0.4 \mathrm{c}$ & $18.1 \pm 0.2 \mathrm{~m}$ & $17.5 \pm 0.5 \mathrm{~d}$ \\
\hline (Lithuania) & 2 & $17.5 \pm 0.1 \mathrm{c}$ & $17.8 \pm 0.3 c$ & $17.1 \pm 0.2 \mathrm{c}$ & $17.8 \pm 0.5 \mathrm{~m}$ & $16.8 \pm 0.1 \mathrm{e}$ \\
\hline
\end{tabular}

Note: The values with different letters in a column are significantly different at $p<0.05$.

\section{Discussion}

Bacterial pathogens belonging to Xanthomonas genus are the causal agents of very devastating diseases of economically important crops worldwide [1,2]. However, in recent decades, the excessive use of pesticides to control plant diseases has caused environmental pollution, harmful effects on organisms, including human health [6]. Thus, biological control promises an alternative sustainable management of plant diseases caused by the genus Xanthomonas [11,13]. The most commonly reported genera with antimicrobial activity against phytopathogens are Actinobacteria, Bacillus, Paenibacillus, Pseudomonas, and Serratia, where Bacillus and Pseudomonas are among the most commonly described genera that can inhibit bacterial plant pathogens $[13,15,33]$. Our studies also found that these two bacterial genera had the greatest antagonistic effect against Xanthomonas spp. strains. The same effectiveness was found with LAB strains, supernatants of Lb. helveticus 148/3, 3, and 14, where average ZOI of endophytic and LAB strains ranged from $23.3 \pm 1.0 \mathrm{~mm}$ to $33.0 \pm 0 \mathrm{~mm}$. Unfortunately, to date, insufficient attention has been paid to finding appropriate biological control measures against $X$. arboricola and $X$. translucens. $X$. oryzae pv. oryzae, $X$. campestris, and $X$. axonopodis pathovars are among the most economically harmful pathogens [2], and therefore, the greatest amount of existing information is on the use of microorganisms to control these pathogens [34,35]. However, several studies have been published on antagonist bacteria suitable for biocontrol against X. arboricola and $X$. translucens. For example, the sweet osmanthus (Osmanthus fragrans) endophyte Bacillus 
$\mathrm{sp}$. is a promising biocontrol candidate for Xanthomonas arboricola pv. juglandis, the causal agent of walnut blight [36].

$\mathrm{LAB}$ are found in food-related environments and also in many plants as endophytic microorganisms [37]. The antagonistic activity of LAB has been described in detail in many studies and now known as producers of various antagonistic compounds, including organic acids, diacetyl, hydrogen peroxide, ethanol, acetaldehyde, acetoine, carbon dioxide, bacteriocins (reuterin and reutericyclin), bactericidal proteins, etc. [38]. Twelve unique LAB strains previously characterized as highly antagonistic were chosen in this study to assess antimicrobial activity against Xanthomonas spp. species. These LAB strains appeared to produce and secrete natural antimicrobial compounds, such as lactic (6.04-19.90 g/L), citric $(0.30-3.30 \mathrm{~g} / \mathrm{L})$, benzoic $(0.2-1.80 \mathrm{mg} / \mathrm{L})$, and sorbic $(0.1-1.20 \mathrm{mg} / \mathrm{L})$ acids, ethanol $(0.30-0.87 \%)$, and hydrogen peroxide $(0.006-0.009 \mathrm{~g} / \mathrm{L})$ [39].

Antagonistic properties of bacteria mostly depend on the ability to produce a wide range of antimicrobials including small bioactive secondary metabolites (bacteriocins, antibiotics, toxins), hydrolytic enzymes, volatile organic compounds, etc. [17,33,40-42]. The genus Lactobacillus is the largest group among LABs, and the most studied and widely described species suitable for biocontrol of plant pathogens is Lb. plantarum [41,43]. Therefore, in our study, we attempted to evaluate Lactobacillus, Streptococcus, and Enterococcus spp. as antagonists that could be used to control pathogenic Xanthomonas spp. bacteria. Our studies showed that all LAB strains tested had antibacterial activity against Xanthomonas spp. The $43 \mathrm{~S}$. thermophilus strains analysed here did not have high antibacterial activity against gram-negative bacteria $(18.8-21.5 \mathrm{~mm})$. The highest activity against Xanthomonas spp. strains was demonstrated by $L b$. helveticus strains $148 / 3$ and 3 . Their activity ranged from 23.3 to $32.0 \mathrm{~mm}$, and they were the best producers of benzoic acid [39]. The most prospective LAB strains tested were $L b$. helveticus $3,148 / 3$, and $\mathrm{R}$ and $\mathrm{Lb}$. reuteri 3 and 7 . In our previous study, Lb. reuteri strains 3 and 7 showed antibacterial activity due to high amount of ethanol production. $L b$. helveticus and $L b$. reuteri strains produced the most of all antimicrobials [39]. Our finding that LAB showed good antibacterial activity against Xanthomonas spp. strongly agrees with previously reported results.

Although many authors describe microorganisms suitable for controlling pathogenic Xanthomonas spp. bacteria [17,33,40-43], the knowledge about the antibacterial activity of bacteria, such as endophytic or LAB strains, is still insufficient. Antagonistic bacteria are a good alternative to manage plant diseases because they do not show toxicity to living organisms and environment and thus are more sustainable compared to chemical pesticides. Bacteria producing a complex of antimicrobial compounds could have great potential for commercial application.

Higher plants are sources of active compounds that are natural pesticides, which can be used against various plant pathogenic bacteria $[16,44]$. They are more attractive than chemical pesticides because are not toxic to the environment and to non-target organisms, including humans, and are easily biodegradable and therefore more sustainable. Essential oils are rich in various groups of chemical compounds that affect the permeability of the bacterial cell membranes and other structures, thus reducing the spread of plant diseases caused by bacterial pathogens $[10,45,46]$.

In the present study, the in-vitro antibacterial activities of essential oils and aqueous extracts of blueberries and cranberries were assessed by the presence or absence of inhibition zones. The results of this in-vitro study showed that $2 \%(v / v)$ essential oils of thyme (Thymus vulgaris), grapefruit (Citrus paradisi), and lavender (Lavandula angustifolia) and aqueous cranberry (Vaccinium vitis-idaea) extracts (Lithuania) exerted potential antibacterial effect against Xanthomonas spp. It is sufficiently well known that the compounds present in these plants have antimicrobial activity against many gram-positive and gram-negative pathogenic bacteria, including bacteria of the genus Xanthomonas [16,32,44,47]. For example, the main components of T. vulgaris are thymol, geraniol, and carvacrol, and they are very effective against gram-negative plant pathogenic bacteria [48]. Our finding that tested essential oils possessed an antibacterial activity against Xanthomonas spp. agrees with 
others previously reported. The $1 \%(v / v)$ essential oils of lemon, pine, silver fir, juniper, rosemary, and peppermint had no antibacterial activity. Some of these findings about Xanthomonas species were confirmed by previous studies, for example, juniper had no antibacterial activity for Xanthomonas campestris pv. campestris (Xcc), but some results were an opposite when Xcc were highly sensitive to rosemary; very sensitive to peppermint, silver fir, and lemon; and sensitive to pine [49] and had no effect. Thus, the results only confirm once again that the activity of the compounds against pathogens is highly dependent on the species of pathogenic microorganism tested and (or) the mode of action of the active compounds of the plant used.

Various publications mention plant extracts or essential oils that may be effective against bacterial microorganisms, and they be used to inhibit the growth of plant pathogenic bacteria in an agricultural system [10,12,16,17,31,32,44,47]. Interest in plant pathogenic bacteria of the genus Xanthomonas is still relevant, as it still causes significant yield losses, and effective and safe measures are being sought to control them. In this context, plant essential oils or their extracts can have promising uses because they are more environmentally friendly and sustainable, and trends in their use seem promising. Thus, many of the secondary metabolites present in plants as active compounds can be used for plant protection and food safety to ensure pathogenic Xanthomonas control [10,12,44]. However, much research still needs to be done to increase the reliability and effectiveness of these products. In this sense, the recent developments in biotechnology and analytical chemistry can help advance studies involving the biological control Xanthomonas.

\section{Conclusions}

Pseudomonas sp. strain NRCIB P2 (average ZOI ranged from $23.00 \pm 0.47 \mathrm{~mm}$ to $33.00 \pm 0 \mathrm{~mm}$ ) had a stronger inhibitory effect on pathogenic Xanthomonas spp. compared to other endophytic bacteria as Bacillus or Paenibacillus spp. However, Paenibacillus sp. NRCIB PB1 had significantly greater inhibition against X. translucens NRCIB X6 (average zone of inhibition $30.28 \pm 0.25 \mathrm{~mm}$ ) compared to $X$. arboricola strains (average zone of inhibition ranged from $16.43 \pm 0.58 \mathrm{~mm}$ to $20.68 \pm 0.33 \mathrm{~mm}$ ).

The supernatants of Lactobacillus helveticus strains 3, 148/3, and $\mathrm{R}$ and Lb. reuteri strains 3 and 7 and Pseudomonas sp. NRCIB P2 demonstrated a strong/potent antibacterial effect against the growth of Xanthomonas spp. strains. The diameter of the inhibition zones under their influence ranged from $24.5 \pm 0.6 \mathrm{~mm}$ to $32.0 \pm 0.8 \mathrm{~mm}$, whereas the diameter of inhibition zones of the control sample (1\% copper sulfate) ranged from $28.3 \pm 1.0 \mathrm{~mm}$ to $29.8 \pm 0.5 \mathrm{~mm}$.

The antibacterial properties of $2 \%(v / v)$ thyme (Thymus vulgaris) essential oils showed a moderate and strong antibacterial activity against Xanthomonas spp. strains' growth. The thyme essential oil formed inhibition zones $18 \pm 0.1-28 \pm 0.2 \mathrm{~mm}$ in diameter. Grapefruit (Citrus paradisi) and lavender (Lavandula angustifolia) 2\% (v/v) essential oils showed a moderate antibacterial activity against Xanthomonas spp. strains' growth (the diameter of inhibition zones were $11.0 \pm 0.1-14.5 \pm 0.5 \mathrm{~mm}$ and $13.5 \pm 0.0-15.5 \pm 0.1 \mathrm{~mm}$, respectively). The minimum inhibitory concentration of thyme essential oil was $7.8 \mu \mathrm{g} / \mathrm{mL}$ and for lavender and grapefruit $31.25 \mu \mathrm{g} / \mathrm{mL}$. The $2 \%(v / v)$ essential oils of lemon (Citrus limon), pine (Pinus sylvestris), silver fir (Abies sibirica), and juniper (Juniperus communis) did not show antimicrobial activity on Xanthomonas spp. strains' growth.

The inhibitory effect of aqueous blueberry extracts against Xanthomonas spp. strains was not dependent on region and location. Aqueous cranberry extracts (Lithuania) showed a sufficiently moderate antibacterial activity (the diameter of the inhibition zones ranged from $16.8 \pm 0.0 \mathrm{~mm}$ to $18.1 \pm 0.0 \mathrm{~mm}$ ), while aqueous blueberry extracts (Lithuania, Latvia, Norway, and Finland) showed a weak antibacterial activity (the diameter of the inhibition zones ranged from $10.0 \pm 0.0 \mathrm{~mm}$ to $13 \pm 0.0 \mathrm{~mm}$ ).

This information will allow the development of new biopesticides in the future based on targeted scientific researches. These results showed that natural antimicrobials (the supernatants of $L b$. helveticus 3, 148/3, and R; Lb. reuteri 3 and 7 strains; the essential oils 
of thyme, lavender, and grapefruit; and aqueous extracts of Vaccinium vitis-idaea) could be used in the development of new biopesticides to control plant bacterial diseases caused by pathogenic Xanthomonas species.

Author Contributions: All authors contributed to the study conception and design. Material preparation and data collection was performed by I.M., D.Č. (Dovile Čepukoit), J.Š. and D.B., I.M., D.Č. (Darius Černauskas) and A.Š. analyzed the data. The first draft of the manuscript was written by I.M., D.Č. (Dovile Čepukoit), J.Š. and D.B. and all authors commented on previous versions of the manuscript. All authors have read and agreed to the published version of the manuscript.

Funding: This research received no external funding.

Institutional Review Board Statement: Not applicable.

Informed Consent Statement: Not applicable.

Data Availability Statement: Not applicable.

Acknowledgments: This article was based on a collaboration established by the COST Action CA16107 "EuroXanth: Integrating science on Xanthomonadaceae for integrated plant disease management in Europe", supported by COST (European Cooperation in Science and Technology).

Conflicts of Interest: The authors declare no conflict of interest.

\section{References}

1. Savary, S.; Teng, P.S.; Willocquet, L.; Nutter, F.W., Jr. Quantification and modeling of crop losses: A review of purposes. Annu. Rev. Phytopathol. 2006, 44, 89-112. [CrossRef]

2. Mansfield, J.; Genin, S.; Magori, S.; Citovsky, V.; Sriariyanum, M.; Ronald, P.; Dow, M.; Verdier, V.; Beer, S.V.; Machado, M.A.; et al. Top 10 plant pathogenic bacteria in molecular plant pathology. Mol. Plant Pathol. 2012, 13, 614-629. [CrossRef] [PubMed]

3. Kannan, V.R.; Bastas, K.K. (Eds.) Sustainable Approaches to Controlling Plant Pathogenic Bacteria, 1st ed.; CRC Press: Boca Raton, FL, USA, 2015. [CrossRef]

4. Burdon, J.J.; Zhan, J. Climate change and disease in plant communities. PLoS Biol. 2020, 18, e3000949. [CrossRef] [PubMed]

5. Juroszek, P.; Racca, P.; Link, S.; Farhumand, J.; Kleinhenz, B. Overview on the review articles published during the past 30 years relating to the potential climate change effects on plant pathogens and crop disease risks. Plant Pathol. 2020, 69, 179-193. [CrossRef]

6. Alengebawy, A.; Abdelkhalek, S.T.; Qureshi, S.R.; Wang, M.-Q. Heavy metals and pesticides toxicity in agricultural soil and plants: Ecological risks and human health implications. Toxics 2021, 9, 42. [CrossRef]

7. Lamichhane, J.R.; Osdaghi, E.; Behlau, F. Thirteen decades of antimicrobial copper compounds applied in agriculture. A review. Agron. Sustain. Dev. 2018, 38, 28. [CrossRef]

8. Majumdar, T.D.; Singh, M.; Thapa, M.; Dutta, M.; Mukherjee, A.; Kumar, G.C. Size-dependent antibacterial activity of copper nanoparticles against Xanthomonas oryzae pv. oryzae-A synthetic and mechanistic approach. Colloid Interface Sci. Commun. 2019, 32, 100190. [CrossRef]

9. Behlau, F.; Gochez, A.M.; Jones, J.B. Diversity and copper resistance of Xanthomonas affecting citrus. Trop. Plant Pathol. 2020, 45, 200-212. [CrossRef]

10. Alonso-Gato, M.; Astray, G.; Mejuto, J.C.; Simal-Gandara, J. Essential Oils as Antimicrobials in Crop Protection. Antibiotics 2021, 10, 34. [CrossRef]

11. Marin, V.R.; Ferrarezi, J.H.; Vieira, G.; Sass, D.C. Recent advances in the biocontrol of Xanthomonas spp. World J. Microbiol. Biotechnol. 2019, 35, 72. [CrossRef]

12. Quinto, E.J.; Caro, I.; Villalobos-Delgado, L.H.; Mateo, J.; De-Mateo-Silleras, B.; Redondo-Del-Río, M.P. Food safety through natural antimicrobials. Antibiotics 2019, 8, 208. [CrossRef] [PubMed]

13. Raymaekers, K.; Ponet, L.; Holtappels, D.; Berckmans, B.; Cammue, B.P. Screening for novel biocontrol agents applicable in plant disease management-a review. Biol. Control. 2020, 144, 104240. [CrossRef]

14. Stefani, E.; Obradović, A.; Gašić, K.; Altin, I.; Nagy, I.K.; Kovács, T. Bacteriophage-Mediated Control of Phytopathogenic Xanthomonads: A Promising Green Solution for the Future. Microorganisms 2021, 9, 1056. [CrossRef]

15. Afzal, I.; Shinwari, Z.K.; Sikandar, S.; Shahzad, S. Plant beneficial endophytic bacteria: Mechanisms, diversity, host range and genetic determinants. Microbiol. Res. 2019, 221, 36-49. [CrossRef] [PubMed]

16. Bajpai, V.K.; Kang, S.-R.; Xu, H.; Lee, S.-G.; Baek, K.-H.; Kang, S.-C. Potential Roles of Essential Oils on Controlling Plant Pathogenic Bacteria Xanthomonas Species: A Review. Plant Pathol. J. 2011, 27, 207-224. [CrossRef]

17. Montesinos, E. Antimicrobial peptides and plant disease control. FEMS Microbiol. Lett. 2007, 270, 1-11. [CrossRef]

18. Lelliott, R.A.; Stead, D.E. British Society for Plant Pathology. In Methods for the Diagnosis of Bacterial Diseases of Plants; Published on behalf of the British Society for Plant Pathology by Blackwell Scientific Publications; Oxford Press: Oxford, UK, 1987. 
19. Schaad, N.W.; Jones, J.B.; Chun, W. Laboratory Guide for the Identification of Plant Pathogenic Bacteria, 3rd ed.; American Phytopathological Society: Saint Paul, MN, USA, 2001.

20. Klement, Z. Method for the rapid detection of the pathogenicity of phytopathogenic pseudomonads. Nature 1963, 199, 299-300. [CrossRef] [PubMed]

21. Janse, J.D. Phytobacteriology: Principles and Practice; CABI: Wallingford, UK, 2005.

22. Kałużna, M.; Janse, J.D.; Young, J.M. Detection and identification methods and new tests as used and developed in the framework of COST 873 for bacteria pathogenic to stone fruits and nuts Pseudomonas syringae pathovars. J. Plant Pathol. 2012, 94, 117-126. [CrossRef]

23. Rosling, A.; Landeweert, R.; Lindahl, B.D.; Larsson, K.-H.; Kuyper, T.W.; Taylor, A.F.S.; Finlay, R.D. Vertical distribution of ectomycorrhizal fungal taxa in a podzol soil profile. New Phytologist. 2003, 159, 775-783. [CrossRef]

24. Salah, M.A.; Martinez, I. Universal and rapid salt-extraction of high-quality genomic DNA for PCR-based techniques. Nucleic Acids Res. 1997, 25, 4692-4693. [CrossRef]

25. Maes, M. Fast classification of plant-associated bacteria in the Xanthomonas genus. FEMS Microbiol. Lett. 1993, 113, 161-165. [CrossRef]

26. Lane, D.J. 16S/23S rRNA Sequencing. In Nucleic Acid Techniques in Bacterial Systematic; Stackebrandt, E., Goodfellow, M., Eds.; John Wiley and Sons: New York, NY, USA, 1991; pp. 115-175.

27. NCBI. Available online: https:/ / www.ncbi.nlm.nih.gov (accessed on 3 November 2021).

28. Šalomskienė, J.; Abraitienė, A.; Jonkuvienè, D.; Mačionienè, I.; Repečkienė, J. Selection of enhanced antimicrobial activity posing lactic acid bacteria characterised by (GTG)5-PCR fingerprinting. J. Food Sci. Technol. 2015, 52, 4124-4134. [CrossRef]

29. Rahman, A.; Islam, R.; Al-Reza, S.M.; Kang, S.C. In vitro control of plant pathogenic Xanthomonas spp. using Poncirus trifoliata Rafin. EXCLI J. 2014, 13, 1104-1110. [CrossRef]

30. Soleimani, N.; Kermanshahi, R.K.; Yakhchali, B.; Sattari, T.N. Antagonistic activity of probiotic lactobacilli against Staphylococcus aureus isolated from bovine mastitis. Afr. J. Microbiol. Res. 2010, 4, 2169-2173.

31. Hammer, K.A.; Carson, C.F.; Riley, T.V. Antimicrobial activity of essential oils and other plant extracts. J. Appl. Microbiol. 1999, 86, 985-990. [CrossRef]

32. Chudasama, K.S.; Thaker, V.S. Screening of potential antimicrobial compounds against Xanthomonas campestris from 100 essential oils of aromatic plants used in India: An ecofriendly approach. Arch. Phytopathol. Plant Prot. 2012, 45, 783-795. [CrossRef]

33. Narayanasamy, P. Mechanisms of Action of Bacterial Biological Control Agents. In Biological Management of Diseases of Crops; Springer: Dordrecht, The Netherlands, 2013; pp. 295-429. [CrossRef]

34. Dimkić, I.; Stanković, S.; Nišavić, M.; Petković, M.; Ristivojević, P.; Fira, D.; Berić, T. The Profile and Antimicrobial Activity of Bacillus Lipopeptide Extracts of Five Potential Biocontrol Strains. Front. Microbiol. 2017, 8, 925. [CrossRef]

35. Medeot, D.B.; Fernandez, M.; Morales, G.M.; Jofré, E. Fengycins from Bacillus amyloliquefaciens MEP218 Exhibit Antibacterial Activity by Producing Alterations on the Cell Surface of the Pathogens Xanthomonas axonopodis pv. vesicatoria and Pseudomonas aeruginosa PA01. Front. Microbiol. 2020, 10, 3107. [CrossRef]

36. Fu, B.; Zou, L.; Lee, C.; Wang, L. Antagonism and biocontrol of walnut blight by sweet osmanthus endophytic bacterium OFE17. J. Plant Pathol. 2021, 103, 1243-1252. [CrossRef]

37. Minervini, F.; Celano, G.; Lattanzi, A.; Tedone, L.; De Mastro, G.; Gobbetti, M.; De Angelis, M. Lactic Acid Bacteria in Durum Wheat Flour Are Endophytic Components of the Plant during Its Entire Life Cycle. Appl. Environ. Microbiol. 2015, 81, 6736-6748. [CrossRef]

38. Šalomskienè, J.; Abraitienè, A.; Jonkuvienè, D.; Mačionienè, I.; Repečkienè, J.; Stankienè, J.; Vaičiulytė-Funk, L. Changes in antagonistic activity of lactic acid bacteria induced by their response to technological factors. Agric. Food Sci. 2015, 24, 289-299. [CrossRef]

39. Salomskiene, J.; Jonkuviene, D.; Macioniene, I.; Asta Abraitiene, A.; Zeime, J.; Repeckiene, J.; Vaiciulyte-Funk, L. Differences in the occurrence and efficiency of antimicrobial compounds produced by lactic acid bacteria. Eur. Food Res. Technol. 2019, 245, 569-579. [CrossRef]

40. Fira, D.; Dimkić, I.; Berić, T.; Lozo, J.; Stanković, S. Biological control of plant pathogens by Bacillus species. J. Biotechnol. 2018, 285, 44-55. [CrossRef]

41. Daranas, N.; Roselló, G.; Cabrefiga, J.; Donati, I.; Francés, J.; Badosa, E.; Spinelli, F.; Montesinos, E.; Bonaterra, A. Biological control of bacterial plant diseases with Lactobacillus plantarum strains selected for their broad-spectrum activity. Ann. Appl. Biol. 2019, 174, 92-105. [CrossRef] [PubMed]

42. Shrestha, A.; Kim, B.S.; Park, D.H. Biological control of bacterial spot disease and plant growth-promoting effects of lactic acid bacteria on pepper. Biocontrol Sci. Technol. 2014, 24, 763-779. [CrossRef]

43. Blainski, J.M.L.; da Rocha Neto, A.C.; Schimidt, E.C.; Voltolini, J.A.; Rossi, M.J.; Di Piero, R.M. Exopolysaccharides from Lactobacillus plantarum induce biochemical and physiological alterations in tomato plant against bacterial spot. Appl. Microbiol. Biotechnol. 2018, 102, 4741-4753. [CrossRef] [PubMed]

44. Pandey, A.K.; Kumar, P.; Singh, P.; Tripathi, N.N.; Bajpai, V.K. Essential oils: Sources of antimicrobials and food preservatives. Front. Microbiol. 2017, 7, 2161. [CrossRef]

45. Lo Cantore, P.; Shanmugaiah, V.; Iacobellis, N.S. Antibacterial activity of essential oil components and their potential use in seed disinfection. J. Agric. Food Chem. 2009, 57, 9454-9461. [CrossRef] 
46. Spizzirri, U.G.; Aiello, F.; Carullo, G.; Facente, A.; Restuccia, D. Nanotechnologies: An Innovative Tool to Release Natural Extracts with Antimicrobial Properties. Pharmaceutics 2021, 13, 230. [CrossRef]

47. Vasinauskienè, M.; Radušienè, J.; Zitikaitè, I.; Survilienė, E. Antibacterial activities of essential oils from aromatic and medicinal plants against growth of phytopathogenic bacteria. Agron. Res. 2006, 4, 437-440.

48. Horváth, G.; Szabó, L.; Lemberkovics, É.; Botz, L.; Kocsis, B. Characterization and TLC-bioautographic detection of essential oils from some Thymus taxa. Determination of the activity of the oils and their components against plant pathogenic bacteria. JPC-J. Planar Chromatogr.-Mod. TLC 2004, 17, 300-304. [CrossRef]

49. Popović, T.; Milićević, Z.O.; Violeta, K.; Igor, R.; Vesela, J.; Aleksandra, K.S. A preliminary study of antibacterial activity of thirty essential oils against several important plant pathogenic bacteria. Pestic. Fitomed. 2019, 33, 185-195. [CrossRef] 